\title{
COMPETÊNCIA INFORMACIONAL NO INSTITUTO FEDERAL DE EDUCAÇÃO, CIÊNCIA E TECNOLOGIA DA PARAÍBA - IFPB: UM ESTUDO DO PROJETO PEDAGÓGICO
}

\section{ALFABETIZACIÓN INFORMACIONAL EN EL INSTITUTO FEDERAL DE EDUCACIÓN, CIENCIA Y TECNOLOGÍA DE PARAÍBA - IFPB: UN ESTÚDIO DEL PROYECTO PEDAGÓGICO.}

\begin{abstract}
Valmira Perucchi - vperucchi2@yahoo.com.br Mestre em Ciência da Informação, Bibliotecária do Instituto Federal de Educação, Ciência e Tecnologia da Paraíba - IFPB

Beatriz Alves de Sousa - beatrizalvesjp@yahoo.com.br Mestre em Ciência da Informação, Bibliotecária do Instituto Federal de Educação, Ciência e Tecnologia da Paraíba - IFPB.
\end{abstract}

\section{Resumo}

Apresenta resultados de pesquisa que teve o objetivo de verificar, no projeto pedagógico do Instituto Federal de Educação, Ciência e Tecnologia da Paraíba (IFPB), a existência de propostas voltadas para o desenvolvimento de competência informacional nos estudantes dessa Instituição. O estudo se baseia nas três concepções de competência informacional abordadas por Belluzzo e Rosetto (2005) e Dudziak (2003): na concepção de se "construir conhecimento", na concepção "digital" e na concepção da "informação social", com ênfase no aprendizado ao longo da vida. Trata-se de uma pesquisa documental, de abordagem qualitativa, fundamentada na literatura da área. Os resultados apontam para a ausência de propostas voltadas para a competência informacional concernente à inclusão digital, à educação continuada e ao desenvolvimento do espírito investigativo no estudante. De acordo com a literatura da área, essas são práticas de grande importância como potencializadoras do bom uso da informação e de obtenção de conhecimentos.

\section{Palavras-chave}

Competência informacional. Educação para a competência informacional. Projeto Pedagógico. Instituto Federal de Educação, Ciência e Tecnologia da Paraíba. 


\section{INTRODUÇÃO}

Apesar dos projetos educacionais incluírem várias competências no sentido de melhorar o processo de ensino aprendizagem, de acordo com a literatura pesquisada, ainda não se discutiu amplamente sobre a implementação de um projeto educacional voltado para a competência em informação. Segundo Dudziak (2003), tal competência exige uma transformação nos papéis sociais e profissionais atuais, no âmbito da comunidade educacional e ante à sociedade.

Para que seja implantado um projeto pedagógico com base em competência informacional, diferentes situações de aprendizagem devem ser trabalhadas de forma que os envolvidos possam, efetivamente, compreender suas necessidades de informação e aprendam a buscar e usar, com eficiência, esses recursos.

Para tanto, a criação e implantação de políticas de formação em competência informacional são necessárias, com vistas a contribuir para a formação educacional e profissional do cidadão, como sugere Cavalcante (2006). A autora expressa que se torna primordial a elaboração e implantação de políticas de formação em competência informacional, planejada e elaborada por profissionais de diferentes áreas, juntamente com setores estratégicos da administração, estudantes, pesquisadores, bibliotecários, profissionais da área de informática e representantes da sociedade. Estes últimos poderão contribuir com indicações de necessidades voltadas para o mercado de trabalho.

Assim, criar práticas que conduzam ao desenvolvimento de competência informacional é uma questão, no nosso entender, atinente à formação educacional, profissional e à qualificação para a cidadania. A construção dessa prática deve ocorrer de forma multidisciplinar, e deve ser desenvolvida com base em cada realidade.

Entendemos que o desenvolvimento de competência informacional é imprescindível a qualquer profissional, já que a informação é um recurso de suma importância a todas as atividades humanas. Sendo assim, desenvolvemos essa pesquisa com o objetivo de verificar a existência de propostas pedagógicas no Instituto Federal de Educação, Ciência e Tecnologia - IFPB que enfatizem o desenvolvimento de competência informacional nos estudantes dessa instituição. Para tanto, analisamos o Projeto Pedagógico Institucional - PPI que consta no Plano de Desenvolvimento Institucional - PDI.

\section{COMPETÊNCIA INFORMACIONAL: COMO DESENVOLVÊ-LA?}

O desenvolvimento de competência em informação é considerado por Garcia (2006) como um processo cultural, portanto, dependente de governos, instituições e da sociedade em geral, sobretudo, dos profissionais da informação. Para o autor, a inserção de competência informacional designa potencializar a sociedade para o uso eficiente da informação, com vistas à obtenção de conhecimentos. No dizer de Lau (2007), o desenvolvimento da competência em 
informação é o primeiro passo na consecução das metas educacionais de qualquer aprendiz. Essa competência deve ter um lugar durante toda a vida dos cidadãos e, principalmente, em seu período acadêmico.

Os processos de aprendizagem segundo Whitworth (2006, tradução nossa) são cada vez mais dedicados a aprender sobre, e não voltados aos problemas presentes no ambiente que vivemos. $\mathrm{O}$ autor analisa a competência informacional na perspectiva da teoria social para a qual a teoria crítica é uma força viva desenvolvida em relação aos problemas contemporâneos.

Assim sendo, considera-se essencial a fomentação de pesquisas nas áreas relacionadas com o desenvolvimento de competência em informação, principalmente no campo da Ciência da Informação e da Educação. É indispensável também aprofundar os meios de se avaliar a alfabetização em informação, reconhecendo que o problema não se encontra entre os que são ou não são informados, mas envolve aspectos mais amplos de aquisição de competências para reconhecer as necessidades de informação e saber satisfazêlas.

É sabido que vários fatores dificultam o acesso à informação e o uso que se faz dela. Segundo Garcia (2006, p. 80) vão "[...] desde o nível de dificuldade ou facilidade na operação de máquinas digitais, até fatores sociais, políticos, econômicos, educacionais, de diferenças físicas ou cognitivas, entre outros". Vivese na sociedade da informação, na qual, todos os indivíduos precisam continuamente construir e reconstruir conhecimentos, demandando muitas informações que se encontram em fontes diversas, o que dificulta sua recuperação. Isso mostra que o simples fato de termos informações disponíveis em diversas fontes não é suficiente para a utilização plena desses recursos. Esse fato é ratificado por Takahashi, quando refere que,

$\mathrm{Na}$ nova economia, não basta dispor de uma infra-estrutura moderna de comunicação; é preciso competência para transformar informação em conhecimento. É a educação o elemento chave para a construção de uma Sociedade da Informação e condição essencial para que pessoas e organizações estejam aptas a lidar com o novo, a criar e, assim, a garantir seu espaço de liberdade e autonomia. A dinâmica da Sociedade da Informação requer educação continuada ao longo da vida, que permita ao indivíduo não apenas acompanhar as mudanças tecnológicas, mas, sobretudo inovar. [...]. As tecnologias de informação e comunicação podem prestar enorme contribuição para que os programas de educação ganhem maior eficácia e alcancem cada vez maior número de comunidades e regiões (TAKAHASHI, 2000, p. 6).

Nesse sentido, é tarefa das instituições de ensino organizar um movimento global aproveitando-se de toda essa riqueza de informações e de inovações tecnológicas para instigar seus estudantes a desenvolver competências e, inclusive de informação. Saber selecionar e rever criticamente a informação é fundamental para articular o conhecimento no mundo atual. 
Para Perrenoud (2000), competência é a faculdade de mobilizar um conjunto de recursos cognitivos (saberes, capacidades, informações etc.) para solucionar uma série de problemas. $O$ autor relacionou dez pontos (competências) que são absolutamente importantes saber a fim de que se possa ensinar bem numa sociedade em que o conhecimento está cada vez mais acessível. São eles:
1) Organizar e dirigir situações de aprendizagem;
2) Administrar a progressão das aprendizagens;
3) Conceber e fazer evoluir os dispositivos de diferenciação;
4) Envolver os alunos em suas aprendizagens e em seu trabalho;
5) Trabalhar em equipe;
6) Participar da administração escolar;
7) Informar e envolver os pais;
8) Utilizar novas tecnologias;
9) Enfrentar os deveres e os dilemas éticos da profissão;
10) Administrar a própria formação.

Uma instituição de ensino, na visão de Gadotti (2000), precisa ser independente e autônoma para criar oportunidades de aprendizagens para seus educandos; precisa saber ensinar a ensinar; ensinar a pesquisar; ensinar a ter raciocínio lógico; a fazer sínteses e elaborações teóricas; a saber organizar os seus próprios trabalhos; a ser disciplinado e aprendiz de forma autônoma, presencial e a distância.

Em outras palavras, pode-se dizer que para atender à dinâmica da sociedade da informação, a instituição de ensino precisa reestruturar seus currículos, planejar-se em médio e em longo prazo, fazer sua própria inovação, ser pró-ativa e susceptível às mudanças, criar e desenvolver modelos de aprendizagem contínua. Nesse contexto, ressalta-se o modelo proposto por Delors* $^{*} 2000$ apud CAVALCANTE 2006, p.54) que aponta como a principal necessidade da sociedade do conhecimento "uma aprendizagem ao longo de toda a vida, fundamentada nesses quatro pilares: aprender a conhecer, aprender a fazer, aprender a viver junto e aprender a ser".

Com base nos relatos anteriores, é válido destacar que dar a outrem a oportunidade de acesso à informação e de uso é ideal para gerar um ambiente de crescimento intelectual, pessoal e social. Tal fato mostra a importância de práticas educacionais voltadas para o desenvolvimento de competência informacional, nas instituições de ensino, para capacitar os indivíduos a lidar e a interagir com a crescente quantidade de informação que demanda da sociedade de informação.

Vitorino (2007) considera oportuno que profissionais da informação se envolvam em pesquisas sobre a competência informacional. Esse é um tema

\footnotetext{
* Esse modelo foi elaborado pelo economista francês Jacques Delors (1999), junto à Comissão Internacional sobre a Educação para o século XXI, através da UNESCO, 2000.
} 
ainda em construção, mas que é apontado por vários autores como um caminho para a ampliação da biblioteca e a valorização do profissional bibliotecário e que trará grande contribuição para a sociedade da informação.

Algumas reflexões sobre a promoção da competência informacional estão sendo apresentadas a seguir.

\section{PROMOÇÃO DA COMPETÊNCIA INFORMACIONAL NA EDUCAÇÃO: REFLEXÕES}

A evolução histórica da competência informacional nos mostra que, nos países desenvolvidos, ela não tem se baseado apenas no debate científico, mas em práticas consistentes de ação política (MELO; ARAÚJJ, 2007).

Segundo a Association of College and Research Libraries - ACRL, a competência informacional é a base da educação continuada, comum a todas as disciplinas, a todos os contextos de aprendizagem e a todos os níveis de educação. Permite que os estudantes apreendam melhor os conteúdos, desenvolvam suas pesquisas, tornem-se autônomos e exerçam mais controle sobre a própria aprendizagem (ACRL, 2000 apud CAVALCANTE, 2006).

Com o objetivo de desenvolver habilidades em informação a Federação Internacional da Associação de Bibliotecas e Instituições - IFLA, estabeleceu diretrizes que constituem um modelo conceitual para orientar a criação de programas de Desenvolvimento de Habilidades em Informação - DHI. As diretrizes são direcionadas a bibliotecas universitárias e escolares, no entanto, para que seus elementos se ajustem melhor às necessidades nacionais ou locais elas podem ser revisadas, modificadas ou adaptadas pelos bibliotecários, de acordo com as necessidades de suas instituições. O único requisito dos direitos autorais para este documento é citá-lo (LAU, 2007)*.

Os padrões de DHI da IFLA estão agrupados sob os três componentes básicos: Acesso, Avaliação e Uso, conforme o Quadro 1.

Whitworth (2006, tradução nossa) vê a competência informacional como um campo de oportunidades para a educação, pois, o estudante pode determinar a natureza e extensão da informação necessária; acessar as informações de forma eficaz e eficiente; avaliar criticamente as informações e suas fontes; usar efetivamente a informação para um propósito específico; e compreender as questões que envolvem uso e acesso a informação.

No Brasil, o modelo das competências surge com a reforma educacional implementada com a Lei 9394/96 e, a seguir, com os dispositivos de regulamentação no que se refere à educação profissional, Decreto-lei 2208/97 e as Diretrizes Curriculares Nacionais para a Educação Profissional,

\footnotetext{
* Estas diretrizes foram submetidas à revisão pública durante o período de setembro de 2004 a março de 2005. O autor recebeu comentários, sugestões e novas contribuições de vários profissionais da informação.
} 
consubstanciadas no Parecer no 16/99, e na Resolução no 04/99, e nos Currículos Nacionais para a Educação Profissional (DELUIZ, 2001).

Vale salientar que, nas definições de estratégias para aprendizagem, são colocadas práticas interdisciplinares e contextualizadas centradas em competências.

Quadro 1 - Padrões de DHI da IFLA

\begin{tabular}{|c|c|c|}
\hline \multicolumn{3}{|c|}{ COMPONENTES BÁSICOS } \\
\hline \multirow{8}{*}{  } & \multirow{4}{*}{ 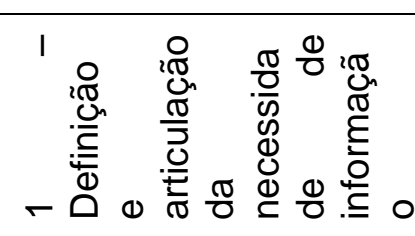 } & $\begin{array}{l}\text { Define ou reconhece a necessidade de } \\
\text { informação; }\end{array}$ \\
\hline & & Decide fazer algo para encontrar a informação. \\
\hline & & Expressa e define a necessidade de informação. \\
\hline & & Inicia o processo de busca. \\
\hline & \multirow{4}{*}{ 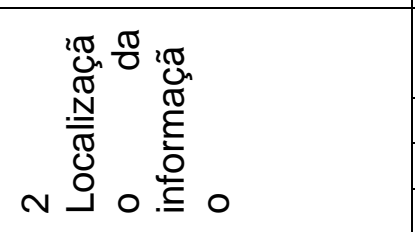 } & $\begin{array}{l}\text { Identifica e avalia as fontes potenciais de } \\
\text { informação }\end{array}$ \\
\hline & & Desenvolve estratégias de busca. \\
\hline & & Acessa fontes de informação selecio \\
\hline & & רa e recupera a inforn \\
\hline \multirow{7}{*}{ 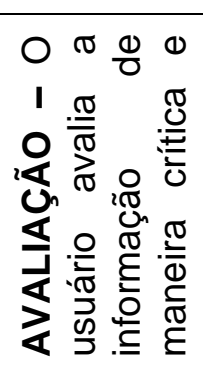 } & \multirow{4}{*}{ 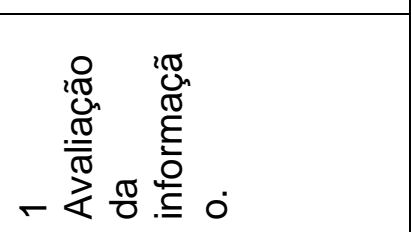 } & Analisa, examina e extrai a informação. \\
\hline & & Generaliza e interpreta a informação. \\
\hline & & Seleciona e sintetiza a informação. \\
\hline & & $\begin{array}{l}\text { Avalia a exatidão e relevância da informação } \\
\text { recuperada. }\end{array}$ \\
\hline & \multirow{3}{*}{ 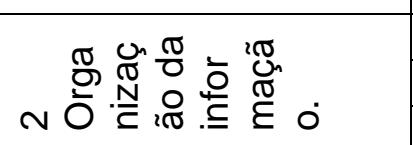 } & Ordena e categoriza a informação \\
\hline & & aniza a informação rec \\
\hline & & If \\
\hline \multirow{7}{*}{ 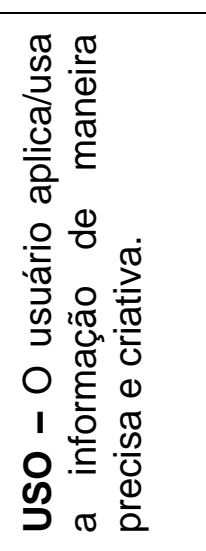 } & \multirow{4}{*}{ 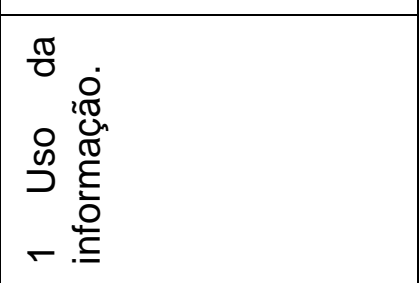 } & $\begin{array}{l}\text { novas formas de comunicar, apresentar e } \\
\text { informação. }\end{array}$ \\
\hline & & Aplica a informação recuperada. \\
\hline & & $\begin{array}{l}\text { Apreende ou internaliza a informação como } \\
\text { conhecimento pessoal. }\end{array}$ \\
\hline & & Apresenta o produto da informação. \\
\hline & \multirow{3}{*}{ 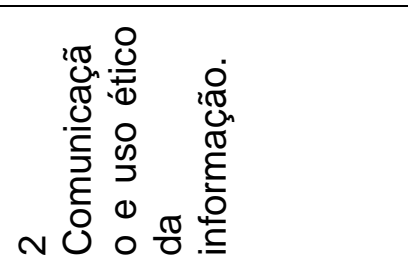 } & $\begin{array}{l}\text { Compreende o uso ético da informação. } \\
\text { Respeita o uso leaal da informacão. }\end{array}$ \\
\hline & & $\begin{array}{l}\text { Comunica o produto da informação com } \\
\text { reconhecimento da propriedade intelectual. }\end{array}$ \\
\hline & & $\begin{array}{l}\text { Usa os padrões para o reconhecimento da } \\
\text { informação }\end{array}$ \\
\hline
\end{tabular}

Fonte: Adaptado de Lau (2007).

Como é o caso dos critérios de avaliação no Exame Nacional do Ensino Médio ENEM, elaborados em 2006 que, para serem alcançados, exigem o desenvolvimento de habilidades informacionais, tais como:

I - Construir e aplicar conceitos das várias áreas do conhecimento para a compreensão dos fenômenos naturais, de processos histórico-geográficos, da produção tecnológica e das manifestações artísticas [...] 
II - Selecionar, organizar, relacionar, interpretar dados e informações representados de diferentes formas, para tomar decisões e enfrentar situações problema [...]

III - Relacionar informações representadas em diferentes formas e conhecimentos disponíveis em situações concretas, para construir argumentação consistente [...]

IV - Recorrer aos conhecimentos desenvolvidos na escola para a elaboração de propostas de intervenção solidária na realidade, respeitando os valores humanos e considerando a diversidade sociocultural $[\ldots]$

V - Compreender a proposta de redação e aplicar conceitos das várias áreas de conhecimento para desenvolver o tema, dentro dos limites estruturais do texto dissertativo-argumentativo [...]

VI - Selecionar, relacionar, organizar e interpretar informações, fatos, opiniões e argumentos em defesa de um ponto de vista [...]

VII - Elaborar proposta de intervenção para o problema abordado, demonstrando respeito aos direitos humanos (BRASIL, 2006).

No entanto, conforme Deluiz (2001), a formulação desse modelo e sua implantação nos planos e programas de educação profissional têm ocorrido de forma diferenciada, devido aos seguintes fatores: a ênfase atribuída ao foco no mercado de trabalho, no indivíduo ou ainda, a articulação ou desarticulação entre formação geral e formação profissional.

Em termos de programas institucionais, conforme Dudziak (2003), podem ser citados os seguintes: PROESI da Universidade de São Paulo; o prêmio Carol Kuhlthau, oferecido pela Escola de Ciência da Informação da Universidade Federal de Minas Gerais - UFMG, e um grupo de pesquisa da Universidade Federal da Paraíba - UFPB que estuda usos e impactos da informação no desenvolvimento de teorias e aplicações sobre a temática da competência informacional (MELO; ARAÚJO, 2007).

De acordo com Campello (2003), desde a década de 50, os bibliotecários já vislumbravam que a biblioteca poderia constituir-se em um espaço para o desenvolvimento de aprendizagens condizentes com as teorias educacionais centradas no aluno. Para a autora, estratégias didáticas centradas no professor e no livro-texto não dão conta de desenvolver as habilidades consideradas essenciais para se sobreviver na sociedade da informação. Ela insiste em chamar a atenção para o potencial que a biblioteca apresenta para o desenvolvimento dessas habilidades, mostrando as possibilidades de uso de teorias que embasam estratégias adequadas de aprendizagem que ainda não são exploradas com profundidade.

\section{PROCEDIMENTOS METODOLÓGICOS}

Trata-se de um estudo descritivo e exploratório com abordagem qualitativa, realizado por meio de uma análise documental do PPI do IFPB. A análise desse documento foi realizada partindo do princípio que a competência informacional, além de outras habilidades permite que os estudantes construam seus próprios 
itinerários de formação. Para tanto, foram identificadas as competências destacadas no projeto, consideradas importantes para formação profissional as quais foram elencadas como princípios filosóficos, e a partir desse construto foi possível identificar as competências e habilidades voltadas para 0 desenvolvimento da competência informacional. Os dados foram analisados e discutidos de acordo com a literatura consultada.

O PPI foi desenvolvido com base na educação profissional pela pedagogia das competências estabelecida pelo Decreto no 2.208/97. Construído para atender a missão da Instituição que é "Preparar profissionais cidadãos com sólida formação humanística e tecnológica para atuarem no mundo do trabalho e na construção de uma sociedade sustentável, justa e solidária, integrando o ensino, a pesquisa e a extensão" (BRASIL, 2010) tendo como foco de interesse a aprendizagem ao longo da vida. Além disso, esse documento contem as práticas pedagógicas que orientam as ações, as estratégias, em função do diagnóstico realizado, dos valores definidos e das concepções teóricas escolhidas; para atender às inúmeras e diversificadas questões que surgem entre formação profissional e acadêmica; entre formação básica e multidisciplinar, no que concerne ao desenvolvimento de atividades extracurriculares.

\section{PROPOSTAS DE COMPETÊNCIA INFORMACIONAL NO PROJETO PEDAGÓGICO INSTITUCIONAL DO IFPB}

O PPI é um documento orientador da ação institucional no qual se registram os alvos a serem atingidos, as opções estratégicas a seguir, em função do diagnóstico realizado, dos valores definidos e das concepções teóricas escolhidas e deve constar como parte integrante do PDI.

Segundo Dudziak (2005), desenvolver projetos pedagógicos voltados para a competência em informação significa repensar crenças, práticas e partir para a ação que priorize a atitude de pesquisa, de autonomia crítica e a busca criativa de informações que gerem novos conhecimentos.

O PPI do IFPB serve para orientar os documentos normativos da instituição; explicitar as convicções ideológicas à enunciação dos propósitos gerais da instituição e sua estrutura organizacional elaborada a partir dos princípios norteadores de uma educação que visa preparar o aluno não apenas para um emprego, mas para consolidar uma carreira profissional, que tenha como objetivo principal o aprendizado ao longo da vida. Assim, constata-se que na sua estrutura, o PPI evoca por uma educação promotora da competência informacional ao preparar o estudante para o aprendizado ao longo da vida, o que permite ao indivíduo acompanhar as mudanças e utilizá-las a seu favor.

Trata-se de uma projeção dos valores originados da identidade da instituição, materializados no seu fazer específico; oportuniza a reflexão sistemática, dando sentido e rumo às práticas educativas, contextualizadas no aprendizado do seu corpo discente cuja natureza consiste em lidar com o conhecimento. Adota pressupostos pedagógicos em seus Projetos de Curso, com vistas a formar profissionais conscientes de sua cidadania, preocupados em 
transformar a realidade para se alcançar uma sociedade mais democrática, solidária e humanista (BRASIL, 2010).

Objetivando identificar propostas de uma educação voltada para a competência informacional foi analisado o PPI do IFPB. Foram enumerados os elementos e propostas que enfatizam o desenvolvimento de competências, com diferentes níveis de apropriação, que podem se configurar em caminhos para o desenvolvimento de competência em informação.

Quadro 2 - Princípios metodológicos que norteiam as práticas acadêmicas do IFPB

\begin{tabular}{|c|c|}
\hline PRINCÍPIOS & DESCRIÇÃO \\
\hline $\begin{array}{l}\text { Filosóficos e Teóricos da } \\
\text { Educação Profissional e } \\
\text { Tecnológica }\end{array}$ & $\begin{array}{l}\text { É dirigida para a formação do educando no sentido do } \\
\text { pensar, saber, saber fazer e saber ser nas várias } \\
\text { dimensões frente ao desenvolvimento tecnológico e suas } \\
\text { repercussões sociais. }\end{array}$ \\
\hline $\begin{array}{l}\text { Filosóficos e Teóricos do } \\
\text { Desenvolvimento da } \\
\text { Ciência }\end{array}$ & $\begin{array}{l}\text { Reconhecendo no senso comum o caminho para a } \\
\text { produção do conhecimento prático e pragmático, } \\
\text { reproduzido a partir das trajetórias e das experiências de } \\
\text { vida de um grupo social. }\end{array}$ \\
\hline $\begin{array}{l}\text { Filosóficos e Teóricos da } \\
\text { Formação } \\
\text { Professores }\end{array}$ & $\begin{array}{l}\text { Abrange a formação para o humano; a docência como base } \\
\text { da formação profissional; o trabalho pedagógico como foco } \\
\text { formativo; a sólida formação teórica em todas as atividades } \\
\text { curriculares nos conteúdos especificamente pedagógicos; a } \\
\text { ampla formação cultural; criação de experiências } \\
\text { curriculares que permitam o contato dos alunos com a } \\
\text { realidade da escola, desde o início do curso; incorporação } \\
\text { da pesquisa como princípio de formação; possibilidade de } \\
\text { vivência, pelos alunos, de formas de gestão democrática; } \\
\text { desenvolvimento do compromisso social e político da } \\
\text { docência; e a reflexão sobre a formação do professor e } \\
\text { sobre suas condições de trabalho. }\end{array}$ \\
\hline $\begin{array}{l}\text { Filosóficos e Teóricos } \\
\text { Metodológicos Gerais } \\
\text { da Prática Acadêmica da } \\
\text { Instituição }\end{array}$ & $\begin{array}{l}\text { Contempla a interdisciplinaridade e a contextualização dos } \\
\text { conhecimentos, dirigindo o ensino para a construção do } \\
\text { conhecimento e o desenvolvimento das competências } \\
\text { necessárias para uma atuação no mundo de forma } \\
\text { reflexiva, cooperativa e solidária. }\end{array}$ \\
\hline
\end{tabular}

Fonte: (BRASIL, 2010).

Os primeiros princípios abordados - Os Princípios Filosóficos e Teóricos da Educação Profissional e Tecnológica - no âmbito do IFPB, devem ser compreendidos como a conjugação interativa entre a educação geral e a tecnologia, valorizando e contextualizando os indivíduos no processo, nas tendências e limites da realidade produtiva e social. Esses estão de acordo com Dudziak (2005) quando diz que, favorecer o ensino para a compreensão da realidade faz parte do projeto pedagógico.

Assim, a Educação Tecnológica pretende formar um indivíduo mais crítico e consciente na construção da história do seu tempo frente ao desenvolvimento tecnológico, tendo também uma compreensão de sua formação social. Está, 
portanto, em consonância com Belluzzo e Rosetto (2005) ao utilizar o aprendizado como subsídio para o desenvolvimento de competências e habilidades para a produção de conhecimento e o desenvolvimento social.

Nesse sentido, o PPI do IFPB propõe uma articulação entre formação geral e formação profissional. Foca o mercado de trabalho, sem desarticular o indivíduo do meio, suprimindo um dos problemas questionado por Deluiz, 2001. que enfatizava essa desarticulação.

Para Dudziak (2005), o sistema educacional deve contribuir para a mobilização dos saberes, visando à construção das competências individuais. A escola deve se moldar de forma a desenvolver relações sociais, conteúdos e práticas que levem à formação de jovens aptos a atender e se adequar à sociedade e aos modelos do novo trabalho. Para a autora, o maior desafio consiste em articular um projeto pedagógico que integre a missão educacional da instituição, as práticas curriculares, as práticas pedagógicas, os processos de avaliação, mas que de conta de uma formação que atenda ao novo contexto social.

Nos Princípios Filosóficos e Teóricos do Desenvolvimento da Ciência, o IFPB adota uma ruptura epistemológica da ciência moderna que simboliza o salto qualitativo do conhecimento científico para o conhecimento do senso comum. A instituição considera os preceitos da ciência pós-moderna que valoriza 0 conhecimento do senso comum, não desprezando o conhecimento que produz tecnologia, mas, que, tal como o conhecimento se deve traduzir em autoconhecimento. Assim, o desenvolvimento tecnológico deve traduzir-se em sabedoria de vida. O conhecimento científico ensina a viver e traduz-se em um saber prático em nome do princípio da igualdade do acesso ao discurso, à competência cognitiva e à competência linguística.

Em conformidade com Dudziak (2005), deve-se valorizar a competência enquanto construção da cidadania, baseada na autonomia crescente, no senso crítico, na pró-atividade, na resolução de situações-problema, incorporando a visão social e de aprendizado participativo, contextualizado, significativo e constante, proporcionando dessa forma, uma interatividade entre educadores e os conteúdos.

Para os Princípios Filosóficos e Teóricos da Formação de Professores, o IFPB prevê uma gestão democrática, participativa, com desenvolvimento do compromisso social, formação da docência com base na formação profissional e condição de trabalho. Faz alusão ao trabalho pedagógico como foco formativo, à adaptação de currículos à realidade, ao desenvolvimento cultural e de pesquisas.

Apesar de incorporar a pesquisa como princípio de formação e possibilidade de vivência pelos alunos, enfatizando uma sólida formação teórica em todas as atividades, não fica evidente a garantia de acesso e uso da informação para a geração de novos conhecimentos, como propõem Belluzzo e Rosetto (2005). Para as autoras, as práticas pedagógicas devem ser planejadas com base na filosofia de uma educação para todos, e estabelecerem ações que visam à promoção da leitura e da pesquisa, enquanto forma de garantir acesso e uso da informação para a geração de novo conhecimento. 
Com relação aos Princípios Filosóficos e Teóricos Metodológicos Gerais da Prática Acadêmica do IFPB, as práticas pedagógicas devem estar vinculadas a um processo reflexivo constante, bem como a uma perspectiva que considere a aprendizagem como um processo dinâmico, resultado das múltiplas relações que se estabelecem entre aquele que aprende (e também ensina); e aquele que ensina ou pretende ensinar (e que igualmente aprende). Deste modo, tais práticas almejam contribuir para que os alunos compreendam a interdependência dos diversos fatores que constituem o ambiente e a realidade nos quais estão inseridos e através de um processo interdisciplinar desenvolvam competências.

Observamos que o PPI do IFPB traz avanços no que concerne ao compromisso social à integração, à gestão democrática e participativa. Alude, ainda, à formação do conhecimento e desenvolvimento de competências necessárias ao desenvolvimento pessoal, mas o referido documento não deixa claro propostas específicas de desenvolvimento de competência em informação, tais como a inclusão digital, a educação continuada e o desenvolvimento do espírito investigativo no estudante, qualificando-o como futuro pesquisador. Práticas educacionais indispensáveis para o desenvolvimento de competência informacional como descritos por (BELLUZZO e ROSETTO 2005; BRASIL, 2006; GADOTTI, 2000; GARCIA, 2006; CAVALCANTE, 2006; DELUIZ, 2001; DUDZIAK, $2003,2005)$ que as categorizam como práticas potencializadoras para o bom uso da informação e para obtenção de conhecimentos.

De acordo com o ponto de vista de Dudziak (2005), o aluno deve ser incentivado a eleger suas próprias prioridades de informação e formação, cabendo aos educadores mostrar caminhos e disponibilizar recursos. Enfatiza também, a educação continuada que se inicia nos primeiros anos da escola e se prolonga por toda a vida, em crescentes níveis de autonomia, levando ao aprender a aprender e a uma formação totalizante. Ainda, para a autora as instituições de ensino ao introduzirem atividades nos projetos pedagógicos que contemplem uma formação totalizante do aluno, com base na competência em informação, incorporam em longo prazo habilidades, conhecimentos e atitudes.

\section{ALGUMAS CONSIDERAÇÕES}

De acordo com nossa análise, a competência é abordada pelo PPI de forma relacionada à qualificação profissional, habilidades necessárias para 0 desempenho profissional. Assim, o projeto pedagógico atende ao debate sobre a qualificação para o mercado de trabalho em geral, a medida que, institucionaliza novas formas de educar e formar profissionais No entanto, o momento atual evidencia outros elementos além dos saberes e dos diplomas, que são importantes na formação do individuo, ou seja, a competência em informação que como bem mostra Barton [2000, tradução nossa] o estudante que possui competência informacional é o senhor de suas próprias aprendizagens, ele vai da simples constatação de fatos para o processo de criação de novas informações, que inclui descobrir informações relevantes, interpretar os dados e informações para a criação de novas idéias. 
A educação é uma atividade prática inata, e um dos problemas enfrentados pela sociedade, pois espera-se que os estudantes adquiram habilidades que os tornem aptos a buscarem soluções nas atividades humanas e como vimos no caso do IFPB é preciso reformular o projeto pedagógico para contemplar o desenvolvimento da competência em informação. Assim, lembramos a preocupação de Dudziak (2003, p. 34), que alerta para a urgência de se estabelecer um "trabalho cooperativo para o desenvolvimento de novas abordagens relativas à filosofia e às práticas educacionais ligadas à competência informacional".

Campello (2003), também, advoga que a formação para competência em informação é um caminho por meio do qual se pode ampliar o espaço da biblioteca no processo pedagógico e sugere o estabelecimento de uma agenda de pesquisa que contemple a temática com aportes teóricos da área de educação. Já Cavalcante (2006) sugere a criação e a implantação de políticas de formação em competência informacional, com vistas a contribuir para a formação educacional e profissional do cidadão para alcançar uma sociedade mais democrática, solidária e humanista.

O PPI do IFPB demonstra claramente o seu compromisso educação formal, mas o referido documento não deixa explicito propostas específicas de desenvolvimento em competência que proporcione a inclusão digital, a educação continuada e a competência em informação que amplia espírito investigativo dos estudantes, qualificando-o como futuro pesquisador, capazes de sozinhos construírem novos conhecimentos.

Espera-se que, além de contribuir cientificamente, porquanto há carência de estudos sistemáticos que enfocam essa temática na área de educação, esta pesquisa sirva também, de subsídio para implantação de práticas pedagógicas que visem o desenvolvimento de competência informacional na referida Instituição, haja vista falhas detectadas.

\section{REFERÊNCIAS}

BARTON, Holly. Information literacy: learning how to learn. [2000]. Disponível em: <http://www.ri.net/RITTI_Fellows/Barton/infolit.html>. Acesso em:: 15 abr. 2011.

BELLUZZO, Regina Célia B.; ROSETTO, Márcia. Contribuição ao desenvolvimento da competência em informação em bibliotecas públicas paulistas: uma experiência com apoio de oficinas de trabalho. In: CONGRESSO BRASILEIRO DE BIBLIOTECONOMIA, DOCUMENTAÇÃO E CIÊNCIA DA INFORMAÇÃO, 21., 2005, Curitiba. Anais... Curitiba: FEBAB, 2005. 1 CD-ROM.

BRASIL. Ministério da Educação. Exame Nacional do Ensino Médio. Brasília, DF: MEC, 2006. (Prova).

Ministério da Educação. Instituto Federal de Educação, Ciência e Tecnologia da Paraíba. Plano de Desenvolvimento Institucional- PDI: 2010-2014. João Pessoa: IFPB, 2010. Disponível em: <http://www.ifpb.edu.br/ arquivos/estatuinte/2010/PLANO_DE_DESENVOLVIMENTO_INSTITUCIONAL.p df>. Acesso em: 04 abr. 2010. 
CAMPELLO, Bernadete. O movimento da competência informacional: uma perspectiva para o letramento informacional. Ciência da Informação, Brasília, v.32, n.3, p.28- 37, set./dez. 2003. Disponível em: <http://www.ibict.br/ciencia dainformacao/>. Acesso em: 03 mar. 2006.

CAVALCANTE, Lídia Eugenia. Políticas de formação para a competência informacional: o papel das universidades. Revista Brasileira de Biblioteconomia e Documentação: Nova Série, São Paulo, v.2, n.2, p.47-62, dez. 2006. Disponível em: <http://www.febab.org.br/rbbd/ojs-2.1.1/index.php/rbbd/article /view/17/5>. Acesso em: 20 fev. 2009.

DELUIZ, Neise. O Modelo das competências profissionais no mundo do trabalho e na educação: implicações para o currículo. Boletim Técnico do SENAC, Rio de Janeiro, v. 27, n. 3, p. 12-25, set./dez. 2001.

DUDZIAK, Elisabeth Adriana. Information literacy: princípios, filosofia e prática. Ciência da Informação, Brasília, v. 32, n. 1, p. 23-35, jan./abr. 2003. Disponível em: < http://revista.ibict.br/index.php/ciinf/article/view/123/104>. Acesso em: 03 mar. 2006.

. Competência em Informação: melhores práticas educacionais voltadas para a Information Literacy. In: CONGRESSO BRASILEIRO DE BIBLIOTECONOMIA, DOCUMENTAÇÃO E CIÊNCIA DA INFORMAÇÃO, 21, 2005, Curitiba. Anais... Curitiba: FEBAB, 2005. 1 CD-ROM.

GADOTTI, Moacir. Perspectivas atuais da educação. São Paulo em Perspectiva, São Paulo, v. 14, n. 2, p. 3-11, abr./jun. 2000. Disponível em: $<$ http://www.scielo.br/scielo.php?script=sci_arttext\&pid=S0102-8839200000020 $0002 \& l n g=e n \& n r m=i s o>$. Acesso em: 03 set 2008.

GARCIA, Rodrigo Moreira. Governo eletrônico, informação e competência em informação. Informação \& Sociedade: estudos, João Pessoa, v.16, n.2, p.79-87, jul./dez. 2006.

LAU, Jesús. Diretrizes sobre desenvolvimento de habilidades em informação para a aprendizagem permanente. Boca Del Rio: IFLA, 2007.

LÜDKE, M.; ANDRÉ, M. E. D. A. Pesquisa em Educação: abordagens qualitativas. São Paulo: EPU, 1986.

MELO, Ana Virgínia Chaves de; ARAÚJO, Eliany Alvarenga de. Competência informacional e gestão do conhecimento: uma relação necessária no contexto da sociedade da informação. Perspectivas Ciência da Informação, Belo Horizonte, v. 12 , n. 2, p. 185-201, maio/ago. 2007. Disponível em:<http:// www.scielo.br/scielo.php?pid=S1413-99362007000200012\&script=sci_arttext \&tIng =ene $>$. Acesso em: 28 ago.2008.

PERRENOUD, Philippe. Dez novas competências para ensinar. Porto Alegre: Artmed, 2000. 
TAKAHASHI, T. (Org.). Sociedade da informação no Brasil: livro verde. Brasília: Ministério da Ciência e Tecnologia, 2000.

VITORINO, Elizete Vieira. Competência informacional do profissional da Informação bibliotecária: construção social da realidade. Encontros Bibli: Revista Eletrônica de Biblioteconomia e Ciência da Informação, Florianópolis, v. 12, n. 24, p. 59-71, 2. sem. 2007. Disponível em: <http://www.periodicos. ufsc.br/index.php/eb/article/view/422/410> Acesso em 28 ago.2008.

WHITWORTH, Andrew. Communicative competence information age: towards a critical theory of information literacy education. ITALICS e-Journal, v. 5, n. 1, p. 113, jan. 2006.

\title{
Title
}

Information Literacy at the Federal Institute of Education, Science and Technology Paraíba - IFPB: a educational project study

\begin{abstract}
This study investigates practices for leveraging information literacy at the educational project of the Federal Institute of Education, Science and Technology - IFPB. The research is grounded on Belluzzo and Rosetto (2005) and Dudziak's (2003) information literacy dimensions: knowledge creation, digital literacy and social information, focusing on the learning progress. The study followed a qualitative approach and a documental analysis grounded on content analysis technique and based on the field literature. The results point out the absence of practices for digital inclusion, continuous education and for stimulating student's investigative capacity, which, according to the field literature, are quintessential for information literacy leverage.
\end{abstract}

\section{Keywords}

Information Literacy. Educational Project. IFPB.

\section{Titulo}

Alfabetización informacional en el Instituto Federal de Educación, Ciencia y Tecnología de Paraíba - IFPB: un estudio del proyecto pedagógico.

\section{Resumen}

Presenta una investigación que tuvo como objetivo verificar en el proyecto pedagógico del Instituto Federal de Educação Ciência e Tecnologia da Paraíba - IFPB la existencia de propuestas volcadas al desarrollo de competencia informacional en los estudiantes de esa institución, tomando como base las tres concepciones abordadas por Belluzzo e Rosetto (2005), Dudziak (2003) - Competencia en información: en la concepción de construir conocimiento; en la concepción digital y en la concepción de información social, con énfasis en el aprendizaje a lo largo de la vida. Se trata de una investigación documental y abordaje cualitativo, fundamentada en la literatura existente en el área. El resultado apunta a la ausencia de propuestas volcadas a la formación de competencia 
informacional en lo que concierne a inclusión digital, educación continuada y desarrollo del espíritu investigativo del estudiante, que de acuerdo con la literatura existente en el área, son de gran importancia potenciar las prácticas en cuanto al uso adecuado de la información y la obtención de los conocimientos.

\section{Palabras clave}

Alfabetización informacional. Educación para la alfabetización informacional. Proyecto Pedagógico. IFPB.

Recebido em: 29/09/2010

Aceito em: 07/05/2011 